\title{
ANALGESIC EFFICACY OF ULTRA-SOUND GUIDED TRANSVERSUS ABDOMINIS PLANE (TAP) BLOCK WITH TOTAL ABDOMINAL HYSTERECTOMY
}

\author{
Ismail Mohammed Abd El Gawad, Ayman Salah Emara, Said Mostafa Abd El Hameed, \\ Mohammed El Shahat Elsayed \\ Anesthesia Department Al Azhar University, Cairo Egypt
}

\begin{abstract}
Background: Pre-incisional bilateral Ultra-sound guided transverses abdominis plane (TAP) block is a novel approach for blocking the abdominal wall neural afferents for postoperative analgesia. The aim of this study is, assess the effectiveness of Ultra-sound guided TAP block on requirement of intraoperative fentanyl and post-operative analgesia in patients undergoing total abdominal hysterectomy. Subjects and Methods: Eighty patients ASA physical status I and II, were randomly allocated into two groups (40 patients each), group TAP: received bilateral Ultra-sound guided TAP block with $20 \mathrm{ml}$ bupivacaine $0.25 \%$ in each side and group $\boldsymbol{G A}$ : received Ultra-sound guided TAP with same volume of normal saline. both groups given standardized GA. Intra-operative fentanyl requirements and postoperative pain using visual analogue score (VAS) at 30 min.1, 2, 3, 6, 12 and 24 h post-operatively were assessed and if VAS $\geq 3$, patients received i.v. pethidine as a rescue analgesic and time to first request of analgesia was recorded. Results: Intra-operative fentanyl requirement reduced in TAP group compared to GA group; it was $100.4 \pm 21.6$ and $150.3 \pm 24.3 \mathrm{mcg}$ respectively. Time to the first analgesic request was also reduced in TAP group compared to GA group; it was112.5 \pm 5.4 min.vs. $23.4 \pm 2.3$ min respectively. VAS at most post-operative measurement points and pethidine requirement were reduced in TAP group compared to GA group; (41.7 and $92.3 \mathrm{mg}$ respectively). There were no recorded complications attributed to the TAP block procedure. All TAP group patients were highly satisfied with their postoperative analgesic regimen. Conclusion: TAP block provides effective intra and postoperative analgesia, prolongs time to the first analgesic request and reduces total intra and postoperative analgesic consumption with minimal PONV after total abdominal hysterectomy.

Keywords: perioperative analgesia, ultrasound guided transversus abdominis plane block.

Corresponding author: Ayman Salah Emara-

Received: 13 September 2015

Tel: 00201100296896

Accepted: 30 September 2015

Email: Aymanbeng@yahoo.com
\end{abstract}

\section{INTRODUCTION}

Postoperative analgesia regimen decreases the stress response to surgery, help in early recovery and ambulation which leads to a better outcome after abdominal surgerie. ${ }^{[1-2]}$ The most common drugs for postoperative analgesia are non-steroidal anti-inflammatory drugs (NSAIDs) and opioids but there are severe side effects of these drugs such as nausea, vomiting, respiratory depression and sedation. Therefore, the use of non-opioid analgesic techniques such as regional and abdominal wall field blocks can lead to good quality of recovery for surgical patients. $^{[3]}$
Transversus abdominis plane (TAP) block, a popular analgesic technique since first described by Rafiin in 2001 as a landmarkbased technique where the needle puncture is performed subcutaneously with a series of 'fascial clicks' within the ilio-lumbar triangle of Petit. ${ }^{[4-5]}$ This triangle is bounded posteriorly by the latissimus dorsi muscle and anteriorly by the external oblique, with the iliac crest forming the base of the triangle, and is a fixed and easily palpable landmark. ${ }^{[6]}$

In TAP block the abdominal wall afferent neurons are blocked by injecting the local anesthetic into the plane between the internal oblique and transverses abdominis muscles, which contain anterior rami of the lower 6 
thoracic nerves (T7 to T12) and the first lumbar nerve (L1) that innervate the anterior abdominal wall (skin, muscles, parietal peritoneum). ${ }^{[7]}$

The transversus abdominis plane (TAP) block, a field block, has subsequently been used for postoperative pain relief in several abdominal surgeries such as large bowel resection, ${ }^{[8]}$ open appendectomy, ${ }^{[9]}$ retropubic prostatectomy, ${ }^{[10]}$ hernia repair, ${ }^{[11]}$ and cesarean section. ${ }^{[12]}$

The blind technique was difficult and may carries potential risk of possible visceral injury, ${ }^{[13]}$ so TAB block was done with ultrasound guidance To minimize these complication. ${ }^{[14-15]}$

The aim of this study were to assess the effect of TAB block on intraoperative, postoperative opioid requirements and postoperative pain scores in the first 24 hours in patients undergoing total abdominal hysterectomy(TAH).

\section{SUBJECTS AND METHODS}

This randomized, controlled, double-blind clinical study was conducted in Bab El-sharia hospital, faculty of medicine, Al-Azhar University, Cairo, Egypt, from September 2014 to july 2015. Patients having a history of allergy to any drug used in this study, body mass index $>30 \mathrm{~kg} / \mathrm{m} 2$, compromised renal and liver function, uncontrolled diabetes, severe cardiovascular, respiratory disease were excluded. After approval of ethics institutional committee and written informed consent, eighty patients ASA physical status I-III, aged between 45 and 64 years were scheduled for TAH by suprapubic abdominal transverse incision and Patients were randomized, by sealed envelopes to two groups (40 patients each). Group TAP: received general anesthesia with bilateral Ultra-sound guided TAP block with $20 \mathrm{ml}$ bupivacaine $0.25 \%$ in each side and group $\boldsymbol{G A}$ : received general anesthesia with Ultra-sound guided TAP with same volume of normal saline.

Electrocardiogram, arterial oxygen saturation, arterial blood pressure and End-tidal carbon dioxide monitoring were attached to patients and after induction of standardized general anesthesia with i.v Fentanyl $(1,5 \mu \mathrm{g} / \mathrm{kg})$, Propofol $(2 \mathrm{mg} / \mathrm{kg})$ and Atracurium $(0.5 \mathrm{mg} / \mathrm{kg})$. Endotracheal tube insertion was performed by an experienced anaesthesiologist after ensuring maximum neuromuscular blocking effect as assessed by train of four (TOF) count $<2$. Anesthesia was maintained with sevoflurane in a concentration of $2 \%$ with $100 \%$ oxygen and mechanical ventilation with an initial tidal volume of $8 \mathrm{~mL} / \mathrm{kg}$ and respiratory frequency of 12 breaths min were used to maintain normocapnia. Group TAP received bilateral ultra-sound guided TAP block with $20 \mathrm{ml}$ bupivacaine $0.25 \%$ in each side and group GA received ultra-sound guided TAP with the same volume of normal saline. The solution was prepared in identical syringes and patients, the anesthesiologists, and the staffs providing postoperative care were blinded to group assignment. Intraoperative fluid requirements must be calculated according to body weight of the patients and intraoperative blood loss must be replaced by fluid or blood transfusion if blood loss more than $20 \%$ of total blood volume of the patient to avoid hemodynamic changes with hypovolemia and to obtain accurate results of intraoperative hemodynamic changes with TAB block. At the end of the surgery, residual neuromuscular block was antagonized by a combination of neostigmine $0.05 \mathrm{mg} / \mathrm{kg}$ and glycopyrolate $0.01 \mathrm{mg} / \mathrm{kg}$. Endotecheal tube was removed at $\mathrm{T} 4 / \mathrm{T} 1$ ratio of $>90 \%$ and the patient fully conscious.

\section{Ultrasound guided TAP}

After complete sterilization, linear ultrasound probe was placed transverse to the abdominal wall between the costal margin and iliac crest. The image produced shows (from above downwards) skin, subcutaneous tissue and fat, external oblique, internal oblique, transversus abdominis. The peritoneum and bowel loops may also be visualized deeper to the muscles. (Figure 1) 


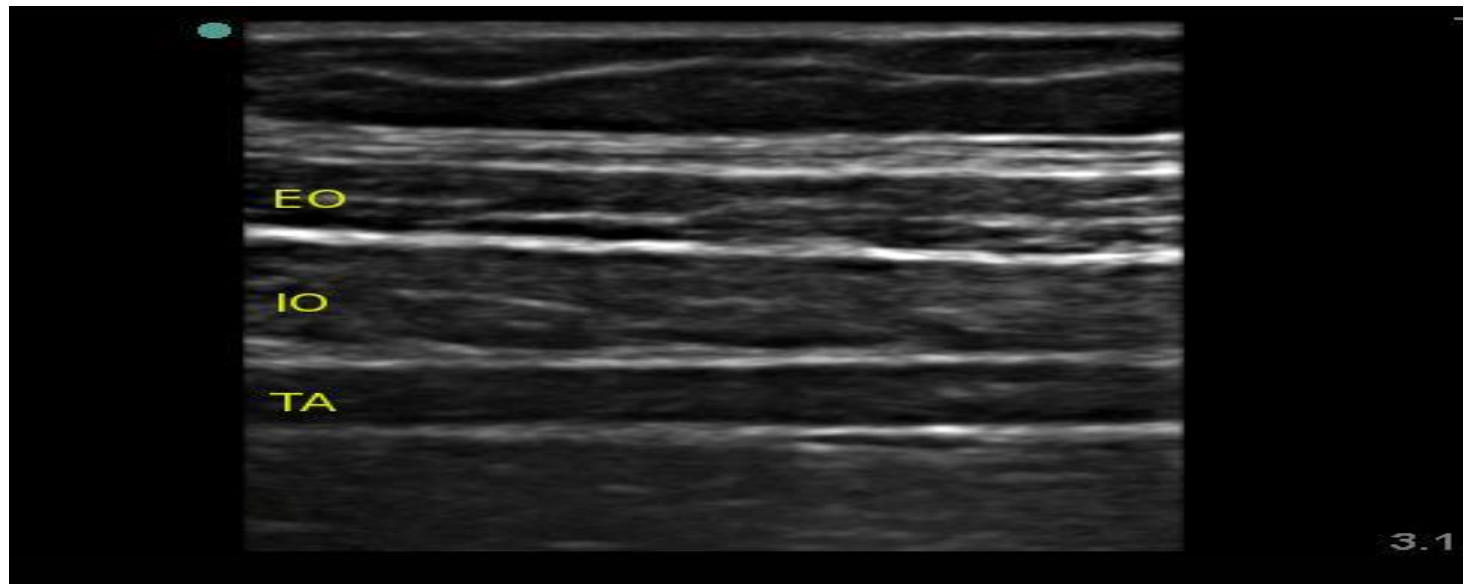

Figure (1): Sono-anatomy of the structures of the abdominal wall. $\mathrm{EO}=$ external oblique, $\mathrm{IO}=$ internal oblique, $\mathrm{TA}=$ transversus abdominis

The needle was introduced in plane and advanced until it reaches the plane between the internal oblique and transversus abdominis muscles. Upon reaching the plane, $2 \mathrm{ml}$ of saline was injected to confirm correct needle position, after which $20 \mathrm{ml} 0.25 \%$ bupivacaine was injected slowly. The transverses abdominis plane was visualized expanding with the injection (Figure 2) then same procedure was done on the other side. Following TAP block the surgical procedure was carried out in usual manner. Intra-operatively, if blood pressure and/or heart rate were increased more than $20 \%$ of basal, $50 \mu \mathrm{g}$ fentanyl was administered and recorded. Postoperative visual analogue score (VAS) for pain was recorded at $0,30 \mathrm{~min}, 1,2$, $3,6,12$ and $24 \mathrm{hrs}$ and if VAS was $\geq 3$, pethidine $1 \mathrm{mg} / \mathrm{kg}$ was received i.v. and time to first analgesic request (min) and also total analgesic consumption were recorded. The incidence and severity of postoperative complications such as nausea and/or vomiting was recorded during the first 24 hour postoperative.

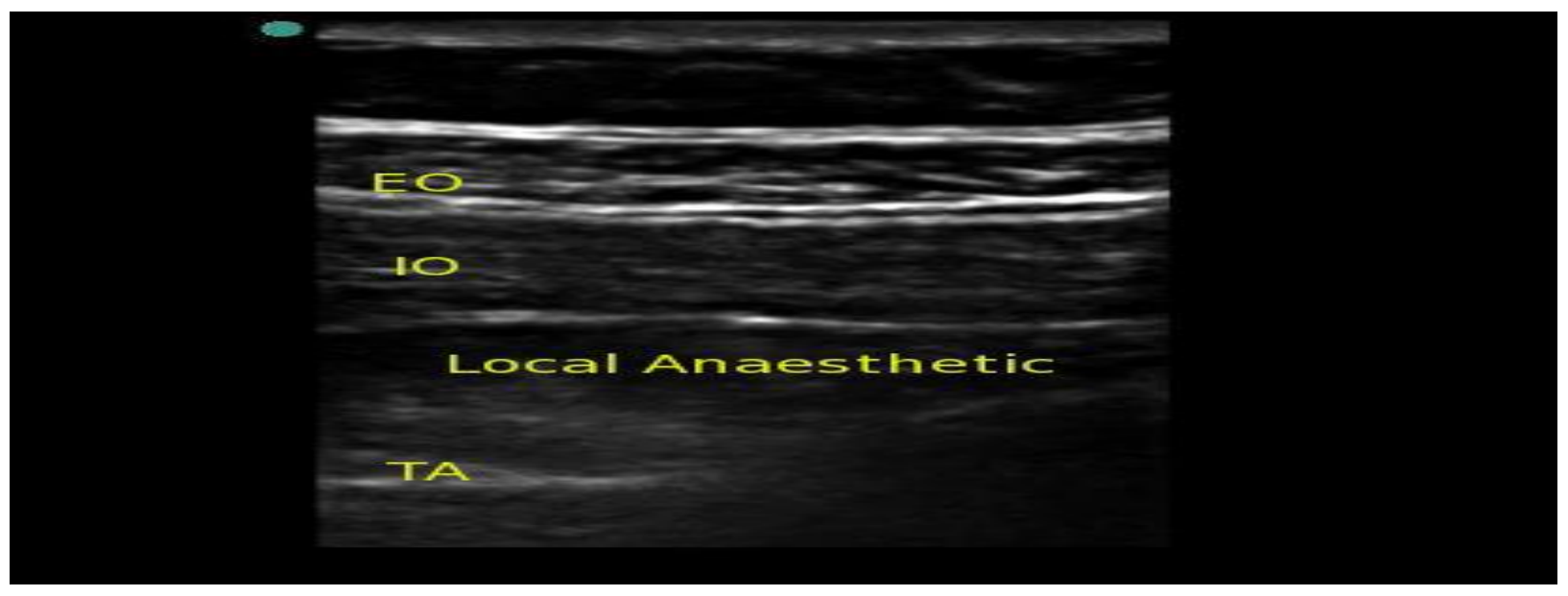

Figure (2): TAP Block after injection of local anesthetic into the transversus abdominis plane.

Statistical Analysis:

SPSS version 17 programs were used to enter data and statistical analysis. Data were presented as Mean $\pm \mathrm{SD}$, range, and number.parametric data in both groups was compared by unpaired Student's $t$-tests, and Mann-Whitney test for nonparametric ordinal data. For data collectedas proportions Chisquared test $\left(\chi^{2}\right)$ and Fisher exact test were performed $P$ value $\quad<0.05$ was considered significant. 


\section{RESULTS}

Patient characteristics, clinical data, the durations of surgergy and anesthesia were comparable (Table 1).

Table (1): Patients characteristics, clinical data, the durations of surgergy and anesthesia.

\begin{tabular}{lcll}
\hline Variable & GA & TAP & P-value \\
Age $(\mathrm{yr})$ & $(n=40)$ & $(n=40)$ & \\
Weight $(\mathrm{kg})$ & $61.3 \pm 8.4$ & $60.9 \pm 7.6$ & 0.823 \\
Height $(\mathrm{m})$ & $66.4 \pm 3.5$ & $65.7 \pm 3.3$ & 0.360 \\
ASA (I-II-III) & $1.63 \pm 0.14$ & $1.66 \pm 0.21$ & 0.454 \\
HR (min) & $17 / 13 / 10$ & $22 / 9 / 9$ & 0.491 \\
MABP(mmhg) & $83.0 \pm 8.7$ & $82.4 \pm 8.4$ & 0.754 \\
Duration of surgery (min) & $108 \pm 7.2$ & $109 \pm 9.6$ & 0.634 \\
& $62.6 \pm 5.6$ & $60.3 \pm 4.9$ & 0.054 \\
Duration of anesthesia (min) & $74.4 \pm 8$ & $72.3 \pm 7.6$ & 0.253 \\
Incision size (cm) & $7.3 \pm 1.8$ & $7.9 \pm 1.5$ & 0.109 \\
\hline
\end{tabular}

Data are expressed as mean \pm SD or number

$\mathrm{HR}=$ heart rate $\mathrm{MABP}=$ mean arterial blood pressure

Intra-operative herat rate and Mean arterial blood pressure were significantly higher in GA group compared to TAP group at all measurements intervals (Figures 3, 4)

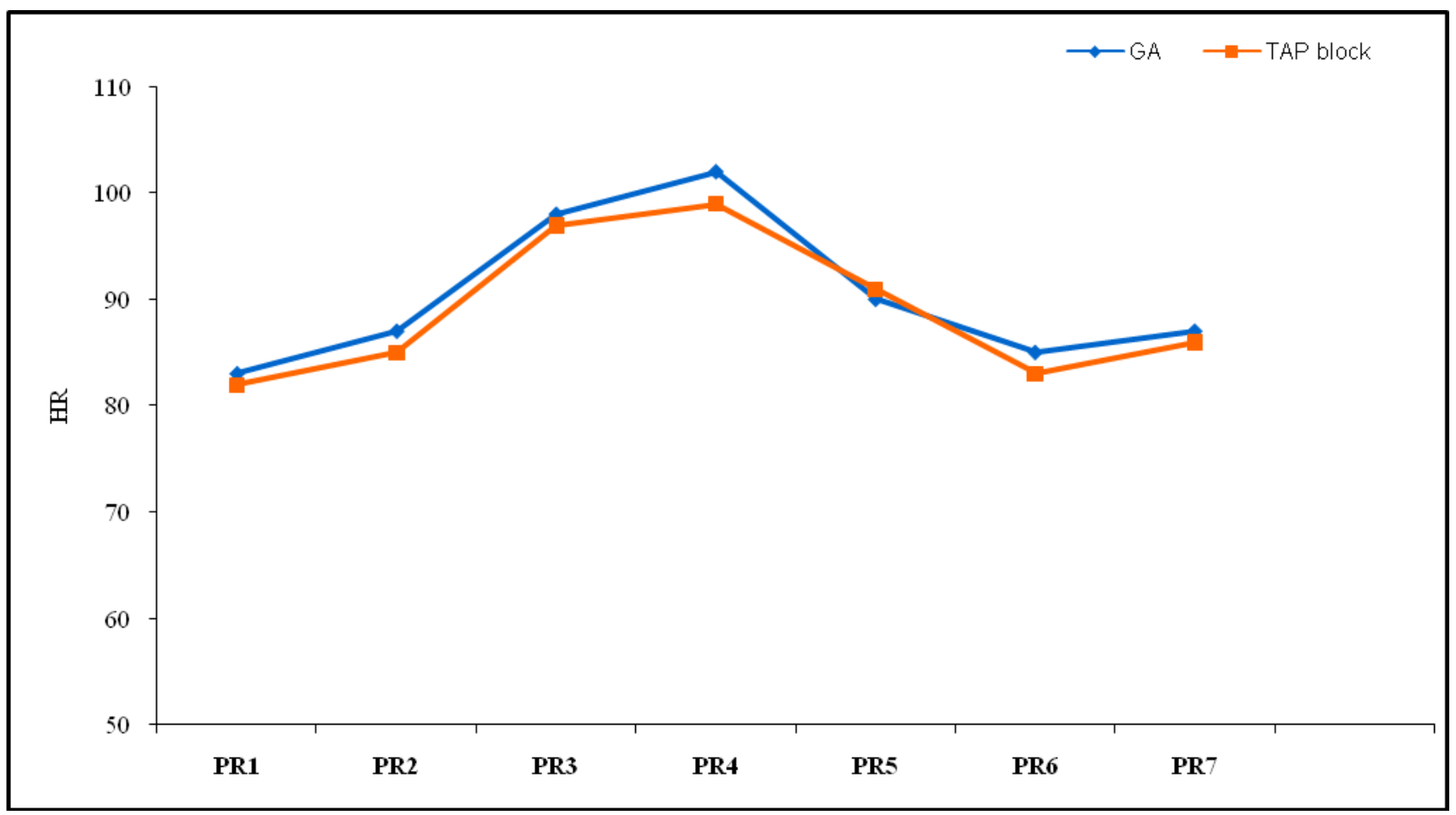

Figure 3.Plse rate, PR1 =before induction, PR2 =after induction.PR3 = 15 min after TAP block, PR4 = after incision, PR5 $=15 \mathrm{~min}$ intraoperative, $\mathrm{PR} 6=30 \mathrm{~min}$ intraoperative, $\mathrm{PR} 7=60 \mathrm{~min}$ intraoperative. 


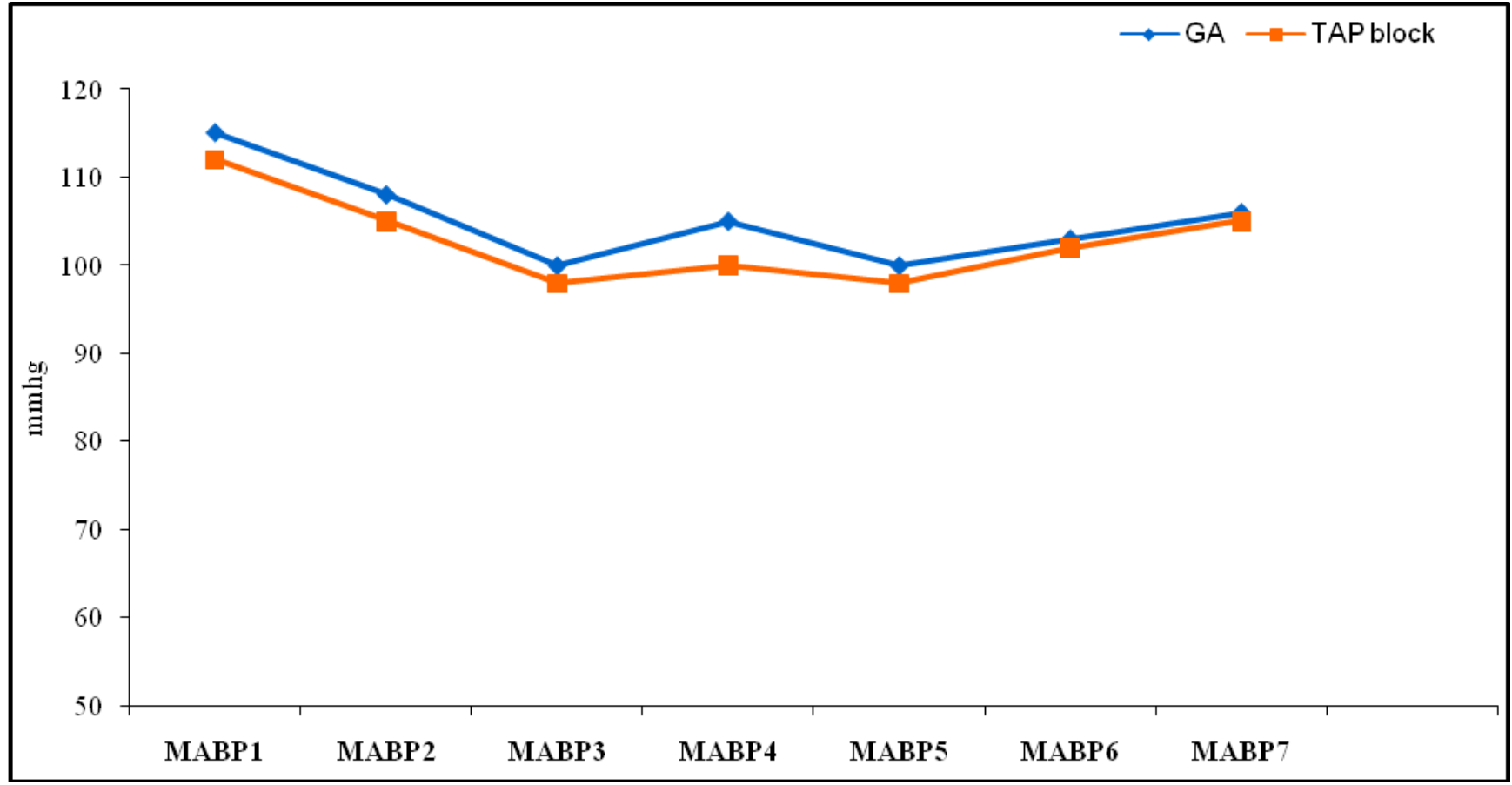

Figure (4): Mean arterial blood pressure, MABP1 =before induction, MABP2 =after induction. MABP3 = 15 min after TAP block, MABP4 = after incision, MABP5 = 15 min intra-operative, $\mathrm{MABP} 6=30$ min intra-operative, $\mathrm{MABP} 7=60$ min intra-operative.

Intraoperative fentanyl requirement was significantly higher in GA group in comparison to TAP group and time to first analgesic request was significantly prolonged in TAP group compared to GA group. Incidence of postoperative nausea-vomiting was none significantly but higher in GA group than TAP group (Table 2). No other complications reported with TAP block.

Table (2): Intraoperative fentanyl requirment, time to requirement of first analgesic (min), and PONV incidence.

\begin{tabular}{l|c|c}
\hline $\begin{array}{l}\text { Variable } \\
\text { P value }\end{array}$ & GA & TAP \\
\hline & $(\mathrm{n}=40)$ & $(\mathrm{n}=40)$ \\
$\begin{array}{l}\text { Intraoperative fentanyl } \\
\text { Requirement(mcg) } \\
<0.001^{*}\end{array}$ & $150.3 \pm 24.3$ & $100.4 \pm 21.6$ \\
$\begin{array}{l}\text { Time to requirement of } \\
\text { first analgesic (min) } \\
<0.001^{*}\end{array}$ & $23.4 \pm 2.3$ & $112.5 \pm 5.4$ \\
$\begin{array}{l}\text { PONV (yes/no) } \\
0.117\end{array}$ & $9 / 31$ & $3 / 37$ \\
\hline
\end{tabular}

Data are expressed as mean $\pm \mathrm{SD}$ or number. $\mathrm{PONV}=$ postoperative nausea-vomiting $*$ = significant to other group.

VAS score in the immediate postoperative period was significantly lower in patients who received TAP block exept at 1 and 3 hours postoperative (Table 3). 
Table (3): Postoperative VAS scores in both groups.

\begin{tabular}{l|c|c}
\hline $\begin{array}{l}\text { Time duration } \\
\text { P value }\end{array}$ & GA & TAP \\
\hline $\begin{array}{l}\text { Significance } \\
0 \text { time(After recovery) } \\
<0.05^{*}\end{array}$ & Mean \pm SD & Mean \pm SD \\
-30 Min & $4.9 \pm 1.4$ & $3.8 \pm 1.2$ \\
$<0.05^{*}$ & $5.1 \pm 1.2$ & $4.0 \pm 1.3$ \\
$-1 \mathrm{hr}$ & $4.3 \pm 0.9$ & $3.9 \pm 0.8$ \\
0.296 & $4.2 \pm 0.7$ & $3.6 \pm 0.9$ \\
$-2 \mathrm{hrs}$ & $3.8 \pm 1.6$ & $3.6 \pm 0.8$ \\
$<0.05^{*}$ & $3.4 \pm 0.7$ & $2.7 \pm 0.5$ \\
$-3 \mathrm{hrs}$ & $2.7 \pm 0.5$ & $2.0 \pm 0.4$ \\
0.481 & $1.6 \pm 0.2$ & $1.4 \pm 0.3$ \\
$-6 \mathrm{hrs}$ & & \\
$<0.001^{*}$ & & \\
\hline$-12 \mathrm{hrs}$ & & \\
$<0.001^{*}$ & & \\
\hline$-24 \mathrm{hrs}$ & & \\
\hline$<0.05^{*}$ & & \\
\hline Data & & \\
\hline
\end{tabular}

Data are expressed as mean \pm SD.

$*=$ significant to other group.

Postoperative pethidine requirement was significantly higher in GA group compared to TAP group(Table 4).

Table (4): Postoperative Pethidine Requirements

\begin{tabular}{l|rc|rrl}
\hline & \multicolumn{2}{|c|}{ GA } & \multicolumn{2}{c}{ TAP } & P value \\
\hline $\begin{array}{l}\text { Pethidine } \\
\text { requirements } \\
\text { 24hrs(mg) }\end{array}$ & Mean & SD & Mean SD & Significance \\
& 92.3 & 9.2 & 41.7 & 7.6 & $<0.001^{*}$ \\
\hline
\end{tabular}

Data are expressed as mean $\pm \mathrm{SD}$.

$*=$ significant to other group.

\section{DISCUSSION}

Our finding in this study demonstrated that TAP block before skin incision reducing intraoperative fentanyl requirements in comparison to placebo, this finding was concomitant with those of Sulgana et $a 1,{ }^{[16]}$ in patients undergoing total abdominal hysterectomy where intraoperative fentanyl consumption significantly lower in patients receiving TAP block with $0.25 \%$ bupivacaine. Mukhtar and Khattak, ${ }^{[1]}$ recorded that, TAP block with $0.5 \%$ bupivacaine in patients undergoing renal transplant recipients were significantly decreasing intra-operative morphine requirments than GA without TAP block $(0.4 \pm$ $1.2 \mathrm{mg}$ vs. $9.3 \pm 1.4 \mathrm{mg}$ ).

El-Dawlatly et al, ${ }^{[18]}$ recordrd that, intraoperative sufentanil consumptions were significantly lower in patients receiving TAB block with laparoscopic cholecystectomy than control group $(8.6 \pm 3.5 \mathrm{mcg}$ vs. $23.0 \pm 4.8$ $\mathrm{mcg})$. Similar findings were reported in a study by $\mathrm{Ra}$ et $\mathrm{al}^{[19]}$ intra-operative remifentanil consumptions were significantly lower in patients receiving TAB block by either $0.5 \%$ or $0.25 \%$ bupivacaine in laparoscopic cholecystectomy. 
The benefits of TAB block and other regional analgesic techniques were reduction in pain intensity, reduction in the postoperative stress response, decreasing side effects from analgesic drugs, improving patient comfort and good surgical outcome with reduction in postoperative morbidity. ${ }^{[20]}$

In the present study, we used pethidine as postoperative analgesia after TAH and its requirements was higher in GA group compared to TAP group. Although intravenous pethidine is a good post-operative analgesic drug but can lead to side effects such as nausea, vomiting, pruritus and respiratory depression. ${ }^{[21]}$ Zhao et $\mathrm{al}^{[22]}$ reported that, Patients with TAP block required less morphine consumption during postoperative 24 hours than those who did not have the block.

The effectiveness of the TAP block in providing immediate postoperative analgesia was assessed and proved by lower VAS score, we demonstrate that the mean postoperative visual analog scale (VAS) pain scores in GA group over the first $24 \mathrm{~h}$ postoperatively was higher compared to the transversus abdominis plane (TAP) block group, which was first demonstrated by Carney et al, ${ }^{[9]}$ who found that, a significant lower postoperative pain scores up to $48 \mathrm{~h}$ and postoperative morphine requirments also decreased up to $48 \mathrm{~h}$ in patients receiving TAP block in total abdominal hysterectomy which correlated with our finding. Those findings are also consistent with McDonnell et al, ${ }^{[8]}$ who found that, the TAP block in patients undergoing surgery via a midline abdominal wall incision were reduce postoperative pain scores with effective and prolonged postoperative analgesia and reduced postoperative opioid requirements both at rest and on movement.

Sulgana et al, ${ }^{[19]}$ who reported, a significantly lower post-operative VAS scores and prolonged postoperative analgesia in patients who received TAP block than control group (290 min vs. $16 \mathrm{~min})$. Sharma et al, ${ }^{[23]}$ also found that, TAB block in patients undergoing major abdominal surgery was improved VAS score in first post-operative $24 \mathrm{~h}$. Petersen et al, ${ }^{[14]}$ also found that, a significant postoperative pain scores in ultrasound guided bilateral TAP block in patients undergoing laparoscopic and also Zhao et al, ${ }^{[22]}$ found that, the pain was reduced at $2 \mathrm{~h}$ after surgery up to $24 \mathrm{~h}$ in TAP group when compared to control group.

In our study, TAB block prolonged the Time to the first postoperative using of analgesic drugs (112 min vs. $23 \mathrm{~min})$. McDonnell et al, ${ }^{[15]}$ recorded that, TAP block with $0.5 \%$ lignocaine in patient undergoing cesarean section produced effective post-operative analgesia and prolonged the Time to the first postoperative using of analgesic drugs for 4-6 h.

A single-shot TAP block technique produces effective analgesia and Reduce postoperative analgesic requirements up to 24 hours. The reasons for the prolonged duration of analgesic effect after single-shot TAP block may related to relatively poorly vascularized this area of block so drug clearance may be delayed and may be due to prolonged action of the amide local anesthetic drug (bupivacaine). ${ }^{[9]}$

In the current study, intra-operative heart rate and mean blood pressure were significantly higher in patients receiving GA compared to TAP block after surgical skin incision but non significantat at all other time points. These results were similar to the results that obtained by Bhattacharjee et al $^{[24]}$ and Sulgana et al. ${ }^{[19]}$ Incidence of postoperative nausea-vomiting was non significant in both groups and no manifestation of local anesthetic drug toxicity or other side effects. These results were similar to the results that obtained by Sulgana et al. ${ }^{[16]}$

\section{CONCLUSION}

Pre-incisional bilateral Ultrasound guided TAP block provides safe and potent intra and postoperative analgesia, reduces intra and postoperative analgesic requirements and less hemodynamic responses to surgical stimuli with minimal adverse effects after total abdominal hysterectomy. 


\section{REFERENCES}

1. Kehlet H, Holte K. Effect of postoperative analgesia on surgical outcome. $\mathrm{Br} \quad \mathrm{J}$ Anesthesia 2001; 87(1): 62-72.

2. Kehlet H. Surgical stress: the role of pain and analgesia Br J Anesthesia1989; 63(2): 18995.

3. White PF. The changing role of non-opioid analgesic techniques in the Management of postoperative pain. Anesth Analg 2005; 101(5): 5-22.

4. Rafi AN. Abdominal field block: a new approach via the lumbar triangle. Anaesthesia 2001; 56(10): 1024-6.

5. Niraj G, Kelkar A, Jeyapalan I, Graff-Baker P, Williams O, Darbar A. Comparison of analgesic efficacy of subcostal transversus abdominis plane blocks with epidural analgesia following upper abdominal surgery. Anaesthesia 2011; 66(6): 465-71.

6. Netter FH. Abdomen posterolateral abdominal wall. In: Netter FH, ed. Atlas of human anatomy summit. New Jersey, USA: The Ciba-Geigy Corporation, 1989; 4:230 40.

7. Griffiths JD, Middle JV, Barron FA, Grant SJ, Popham P.A, Royse CF.Transversus abdominis plane block does not provide additional benefit to Multimodal analgesia in gynecological cancer surgery. Anesthesia Analgesia 2010; 111(3): 797-801

8. McDonnell JG, O'Donnell B, Curley G, Heffernan A, Power C, Laffey JG. The analgesic efficacy of transversus abdominis plane block after abdominal surgery: A prospective randomized controlled trial. Anesth Analg 2007; 104:193-7.

9. Carney J, Finnerty O, Rauf J, Curley G, McDonnell JG, Laffey JG. Ipsilateral transversus abdominis plane block provides effective analgesia after appendectomy in children: A randomized controlled trial. Anesth Analg 2010; 111:998-1003.

10. O'Donnell BD, McDonnell JG, McShane AJ. The transverses abdominis plane (TAP) block in open retropubic prostatectomy. Reg Anesth Pain Med 2006; 12:31-91.
11. Aveline C, Le Hetet H, Le Roux A, Vautier $\mathrm{P}$, Cognet F, Vinet E. Comparison between ultrasound-guided transverses abdominis plane and conventional ilioinguinal/iliohypogastric nerve blocks for day-case open inguinal hernia repair. $\mathrm{Br} \mathbf{J}$ Anaesth 2011; 106:380-6.

12. McDonnell JG, Curley G, Carney J, Benton A, Costello J, Maharaj $\mathrm{CH}$, et al. The analgesic efficacy of transversus abdominis plane block after cesarean delivery: A randomized controlled trial.Anesth Analg 2008; 106:186-91.

13. Lancaster P, Chadwick M. Liver trauma secondary to ultrasound guided transversus abdominis plane block. Br J Anaesthesia 2010; 104:509-10.

14. Walter EJ, Smith P, Albertyn R, Uncles DR.Ultrasound imaging for transverses abdominis blocks. Anaesthesia 2008; 63(2):211.

15. Hebbard P. Subcostal transversus abdominis plane block under ultrasound guidance. Anesth Analg 2008; 106(2):674.

16. Sulagna B, Manjushree R, Tapas G, Souvik M, Amitava L. Analgesic efficacy of transversus abdominis plane block in providing effective perioperative analgesia in patients undergoing total abdominal hysterectomy: A randomized controlled trial. Journal of Anaesthesiology Clinical Pharmacology. Jan 2015; 197 (34): 203.52.

17. Mukhtar K, Khattak I. Transversus abdominis plane block for renal transplant recipients. Br J Anaesth 2010; 104:663-4.

18. El-Dawlatly AA, Turkistani A, Kettner SC, Machata AM, DelviMB, Thallaj A, et al. Ultrasound-guided transversus abdominis plane block: Description of a new technique and comparisonwith conventional systemic analgesia during laparoscopic cholecystectomy. $\mathrm{Br} \quad \mathrm{J}$ Anaesth 2009; 102:763-7.

19. Ra YS, Kim CH, Lee GY, Han JI. The analgesic effect of the ultrasound- guided transverse abdominis plane block after laparoscopic cholecystectomy. Korean J Anesthesiol 2010; 58:362-8. 
20. Capdevila X, Barthelet Y, BibouletP, Ryckwaert Y, Rubenovitch J, Athis F. Effects of Perioperative analgesic technique on the surgical outcome and duration of rehabilitation after major knee surgery. Anesthesiology 1999; 91: 8-15.

21. Stanley G, Appadu B, Mead M,Rowbotham DJ. Dose requirements, efficacy and side effects of morphine and pethidine delivered by patient- controlledanalgesia after gynaecological surgery. Br J Anaesth 1996; 76: 484-6.

22. Zhao X, Tong Y, Ren H, Ding XB, Wang $\mathrm{X}$, Zong JY, et al. Transversus abdominis plane block for postoperative analgesia after laparoscopic surgery: a systematic review and meta-analysis. Int $\mathrm{J}$ Clin Exp Med. 2014; 7(9):2966-75.

23. Sharma P, Chand T, Saxena A, Bansal R, Mittal A, Shrivastava U. Evaluation of postoperative analgesic efficacy of transversus abdominis plane block after abdominal surgery: A comparative study. J Nat Sci Biol Med 2013; 4:177-80.

24. Bhattacharjee S, Ray M, Ghose T, Maitra S, Layek A: Transversus abdominis plane block in abdominal hysterectomy, Journal of Anesthesiology Clinical Pharmacology,JulySeptember 2014; 30(3):391-396. 